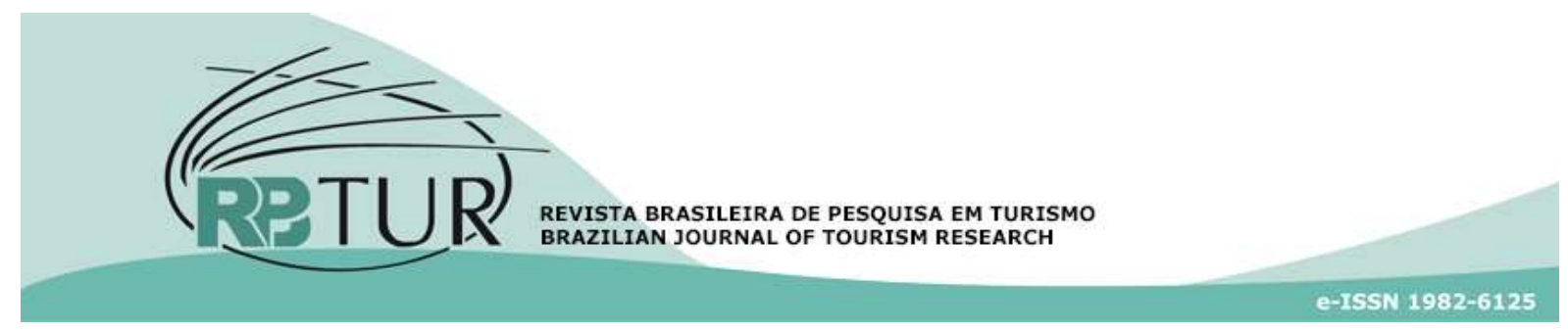

Artigo

DOI: http://dx.doi.org/10.7784/rbtur.v12i2.1379

\title{
"A união faz a força": análise do processo de aprendizagem interorganizacional em uma rede paraibana de hotéis
}

\section{"Many hands make light work": analysis of the interorganizational learning process in a paraiban hotel network}

\section{"La unión hace la fuerza": análisis del procedimiento de aprendizaje interorganizacional en una red paraibana de hoteles}

\author{
Jammilly Mikaela Fagundes Brandão ${ }^{1}$ \\ Joelma Abrantes Guedes Temoteo ${ }^{2}$ \\ Gesinaldo Ataíde Cândido ${ }^{3}$
}

Resumo: Dentre as diferentes motivações que levam as organizações a interagirem está a necessidade de adquirir novas competências que viabilizem inovações de reconhecido valor econômico no mercado. Através da colaboração e alianças, as organizações parceiras podem trocar conhecimentos e aprender umas com as outras. Por outro lado, o principal papel da empresa consiste na administração de seu conhecimento de forma mais eficiente que seus competidores, cabendo a organização identificar e proteger seu conhecimento estrategicamente relevante. Diante desse impasse, esse estudo tem como objetivo analisar como ocorre o processo de aprendizagem interorganizacional em uma rede paraibana de hotéis. Nesse sentido, desenvolveu-se uma pesquisa descritiva de abordagem qualitativa. Para a coleta de dados foram realizadas entrevistas semiestruturadas com quatro gestores do Grupo Casa Branca, que administra atualmente três meios de hospedagem, localizados em João Pessoa-PB. Dentre as principais constatações, foi verificado que há uma constante troca de conhecimentos e uma contínua cooperação entre os gestores dos hotéis do Grupo Casa Branca e

\footnotetext{
${ }^{1}$ Instituto Federal de Brasília (IFB), Brasília, DF. Escolha da temática da pesquisa, definição do problema, objetivo e procedimentos metodológicos da pesquisa, redação do texto, análise e interpretação dos dados.

${ }^{2}$ Universidade Federal da Paraíba (UFPB). Departamento de Turismo e Hotelaria - DTH. João Pessoal, PB. Redação do texto, construção do embasamento teórico, coleta de dados, análise e interpretação dos dados, revisão ortográfica e das normas de formatação.

3 Universidades Federal da Paraíba e Campina Grande UFPB/UFCG. João Pessoa, PB. construção do embasamento teórico e orientação geral do artigo, em especial, nos aspectos teóricos e metodológicos da pesquisa.
}

Artigo recebido em: 17/10/2017. Artigo aceito em: 07/02/2018.

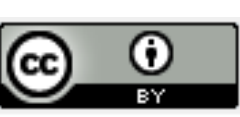


os gestores de outros meios de hospedagem. Foi possível observar ainda que não há uma pressão do ambiente concorrencial das empresas ou competição pelo mesmo mercado, e que a parceria e as alianças, geralmente, são consideradas mais importantes do que as vantagens econômicas isoladas. Como fatores determinantes para essa efetiva cooperação, destaca-se a relação de confiança e a clareza na comunicação.

Palavras-chave: Aprendizagem Interorganizacional. Cooperação. Hotelaria.

Abstract: Among the different motivations that lead organizations to interact is the need to acquire new skills that enable innovations of recognized economic value in the market. Through collaboration and alliances, partner organizations can exchange knowledge and learn from each other. On the other hand, the main role of the company is to manage its knowledge more efficiently than its competitors, and it is up to the organization to identify and protect its strategically relevant knowledge. Faced with this impasse, this study aims to analyze how the process of interorganizational learning occurs in a network of hotels in Paraiba. In this sense, a descriptive qualitative approach was developed. For the data collection, semi-structured interviews were conducted with four managers of the Casa Branca Group, which currently manages three means of lodging, located in João Pessoa-PB. Among the main findings, it was verified that there is a constant exchange of knowledge and a continuous cooperation between the managers of the hotels of the Casa Branca Group and the managers of other means of lodging. It was also possible to observe that there is no pressure of the competitive environment of the companies or competition for the same market, and that the partnership and the alliances are generally considered more important than the isolated economic advantages. As a determining factor for this effective cooperation, the relationship of trust and clarity in communication stands out.

Keywords: Interorganizacional Learning. Cooperation. Hospitality.

Resumen: Entre las diferentes motivaciones que llevan a las organizaciones a interactuar está la necesidad de adquirir nuevas competencias que viabilicen innovaciones de reconocido valor económico en el mercado. A través de la colaboración y alianzas, las organizaciones asociadas pueden intercambiar conocimientos y aprender unas con otras. Por otro lado, el principal papel de la empresa consiste en la administración de su conocimiento de forma más eficiente que sus competidores, correspondiendo a la organización identificar y proteger su conocimiento estratégicamente relevante. Ante este impasse, ese estudio tiene como objetivo analizar cómo ocurre el proceso de aprendizaje interorganizacional en una red paraibana de hoteles. En ese sentido, se desarrolló una investigación descriptiva de abordaje cualitativo. Para la recolección de datos se realizaron entrevistas semiestructuradas con cuatro gestores del Grupo Casa Blanca, que actualmente administra tres medios de hospedaje, ubicados en João Pessoa-PB. Entre las principales constataciones, se verificó que hay un constante intercambio de conocimientos y una continua cooperación entre los gestores de los hoteles del Grupo Casa Blanca y los gestores de otros medios de hospedaje. Es posible observar que no hay una presión del entorno competitivo de las empresas o competencia por el mismo mercado y que la asociación y las alianzas generalmente se consideran más importantes que las ventajas económicas aisladas. Como factores determinantes para esa efectiva cooperación, se destaca la relación de confianza y la claridad en la comunicación.

Palabras clave: Aprendizaje Interorganizacional. Cooperación. Hotelería.

\section{INTRODUÇÃO}

Embora os primeiros estudos sobre aprendizagem datem da década de 1960, o conceito de aprendizagem organizacional recebeu maior atenção no âmbito acadêmico e profissional na década de 1990, ocasião em que a gestão do conhecimento também 
emergiu com maior notoriedade no contexto organizacional, passando a ser frequente a associação de aprendizagem e conhecimento à gestão estratégica (Godoi \& Antonello, 2011; Easterby-Smith \& Lyles, 2011, Takeuchi \& Nonaka, 2008).

Nesse período, a fim de adquirir vantagem competitiva, as organizações passaram a buscar o desenvolvimento de processos inteligentes que pudessem otimizar o processo de gerar, armazenar, organizar, disseminar e aplicar o conhecimento tácito e explícito (Souza, 2004; Silva, 2009; Takeuchi \& Nonaka, 2008). Conforme destacam Nonaka, Toyama e Byosiére (2001), nos últimos anos, muitos estudos evidenciam o conhecimento e a capacidade de criar e utilizá-lo como uma importante fonte de vantagem competitiva organizacional.

Ao analisar os estudos organizacionais, observa-se que há uma predominância da visão dos negócios como uma busca obsessiva e unidimensional pela lucratividade, em que as organizações, inseridas em um contexto capitalista, assumem uma postura extremamente competitiva, muitas vezes negando a importância de metas e pensamento social mais amplos. Contudo, como alternativas a esse modelo predominante estão as abordagens das alianças estratégicas, cooperação empresarial e aprendizagem interorganizacional (Andreis et al, 2014).

As alianças estratégicas podem ser compreendidas como arranjos voluntários entre organizações, abrangendo trocas, compartilhamentos e desenvolvimento conjunto de produtos, tecnologias e serviços (Gulatti, 1998). Seguindo essa abordagem, estão os estudos relacionados à aprendiza-gem interorganizacional (Wegner, 2011; Knight, 2002; Levinston \& Asahi, 1995), que proporcionam uma série de reflexões sobre o modo como são feitos os negócios e o quanto as organizações (e os indivíduos) podem se beneficiar caso suas relações sejam fundamentadas na cooperação, em especial quando esses estudos partem de uma perspectiva em rede (Wegner, 2011) fazendo uso da abordagem sociocultural (Gherardi \& Nicolini, 2001).

Sobre aprendizagem em rede, Wegner (2011, p. 541) destaca que "aprender com os parceiros e trocar conhecimentos é um processo natural, à medida que empresas e indivíduos com habilidades e competências diferentes criam alianças". Child (2011) afirma que as redes realizam trocas de informações e conhecimentos capazes de estimular aprendizagem técnica, sistêmica e até estratégica, no entanto, o autor enfatiza que o tipo de aprendizagem que pode ser gerada depende do propósito, do envolvimento e das necessidades dos parceiros. Além disso, há uma série de fatores moderadores da aprendizagem interorganizacional, como será visto mais adiante, que tanto podem limitar quanto estimular a troca de conhecimentos e a aprendizagem entre as organizações (Child, 2011).

Dentre os estudos de aprendizagem organizacional, há uma predominância de pesquisas que abordam os fenômenos por uma lente reducionista e unidirecional, nas quais são consideradas apenas a dimensão intraorganizacional (Smith, Grupta \& Shalley, 2006). Nesses estudos, a ênfase se restringe à criação e estruturação da aprendizagem organizacional fundamentando-se na relação 
da organização com o seu ambiente, desconsiderando as estratégias que envol-vem as interações de uma organização com outras organizações. Contudo, Wegner (2011, p. 538) destaca que "é o equilíbrio entre esses dois processos de aprendizagem (intra e interorganizacional) que permite explorar oportunidades presentes e futuras".

Reconhecendo a necessidade e relevância da organização aprender tanto com o desenvolvimento interno do conhecimento obtidos e desenvolvidos pela própria organização; quanto com a experiência de outras organizações, considerando a complementaridade entre essas aprendizagens (Wegner, 2011; Knight, 2002; Levinston \& Asahi, 1995; Levinthal \& March, 1993), emergiu o interesse de desenvolver esse estudo, que surgiu a partir dos seguintes questionamentos: Qual a importância das alianças externas no processo de aprendizagem e conhecimentos organizacionais? Como as organizações concorrentes podem ser parceiras? É possível adquirir vantagem competitiva aliando-se a organizações concorrentes? Como as organizações podem trocar conhecimentos por meio meio do processo de aprendizagem interoganizacional e ao mesmo tempo proteger seu conhecimento para que seus processos sejam únicos e não imitáveis?

Partindo dessas constatações e diante de todas inquietações expostas, esse estudo tem como objetivo analisar o processo de aprendizagem interoganizacional de uma rede paraibana de hotéis. $A$ pesquisa foi realizada com gestores de uma rede hoteleira paraibana, que atualmente administra três meios de hospedagem localizados em João Pessoa-PB. A escolha em estudar um caso do segmento hoteleiro da capital do estado da Paraíba se justifica pelo conhecimento disseminado no senso comum de que na hotelaria pessoense há uma forte relação de cooperação entre os gestores de meios de hospedagem. A decisão pelo Grupo em estudo, que atua no mercado desde dezembro de 2011, concretizou-se pelo fato de seus gestores se mostrarem abertos e interessados em participar da pesquisa, já que foram realizados contatos com gestores de uma outra rede paraibana sem sucesso.

Essa pesquisa caracteriza-se como um estudo de caso descritivo de abordagem qualitativa (Yin, 2005). Para a coleta de dados foram realizadas entrevistas semiestruturadas (Manzini, 2003) com quatro gestores da rede hoteleira paraibana: o Grupo Casa Branca. $O$ instrumento de coleta de dados consistia em 20 questões, segmentadas em 4 seções temáticas: 1) perfil do entrevistado, dos meios de hospedagem e da Rede; 2) o processo de aprendizagem interorgani-zacional; 3) a relação de coope-ração/competição e as alianças estratégicas para aprendizagem; e 4) os fatores modera-dores da aprendizagem em rede.

Na próxima seção será abordada a aprendizagem interorganizacional sob uma perspectiva estratégica, destacando os fatores que influenciam esse processo de aprendizagem entre organizações. Na sequência, 
serão apresentados os procedimentos metodológicos utilizados nesse estudo para o alcance do objetivo pré-estabelecido. Em seguida, serão descritos os resultados em três seções: perfil dos sujeitos da pesquisa e da organização em estudo; o processo de aprendizagem interorgani-zacional; elementos moderadores da apren-dizagem de interorganizacional. Por fim, serão apresentadas as considerações finais e as referências que fundamentaram esse estudo.

\section{REFERENCIAL TEÓRICO}

\subsection{Compreendendo o ciclo de aprendi- zagem organizacional}

O processo de aprendizagem no contexto organizacional tem se tornado nas últimas décadas um interessante obje-to/fenômeno de investigação, sustentado pelo argumento de que a aprendizagem é um instrumento de renovação estratégica para a organização, essencial para a sobrevivência em ambientes competitivos e dinâmicos (Andreis et al, 2014).

A aprendizagem organizacional está fundamenta em 4 processos: a aquisição de conhecimento, a distribuição de informação, a interpretação de informação e a memória organizacional. No primeiro processo, a organização adquire conhecimentos obtidos pelo monitoramento do ambiente, fazendo uso de sistemas de informação seja par armazenar ou recuperar informações. No segundo processo, a organização compar-tilha a informação com suas unidades e seus membros, desenvolvendo aprendizagem e a produção ou compreensão de novos conhecimentos. Na sequência, dar-se início ao terceiro processo, momento em que a informação é distribuída e compreendida. Por fim, tem-se o último o processo, que se refere à memória organizacional, considera-da como um armazém no qual todo o conhecimento é guardado para ser utilizado no futuro (Huber, 1991).

De modo bastante semelhante, Starkey (1998) descreve que o ciclo da aprendizagem organizacional compreende quatro estágios: geração e difusão da apren-dizagem, integração de novas informações no contexto organizacional, interpretação coletiva compartilhada das informações e introdução de novas perspectivas.

Observa-se que nos dois modelos (elaborados pelos dois autores anteriormente citados), o processo de aprendizagem tem início com a aquisição de conhecimento, em seguida, há a fase de compartilhamento e, por fim, o processo se encerra com a exploração da memória organizacional. Sob a perspectiva da aprendizagem em rede, esse ciclo ocorre por meio da interação de organizações que pertencem a uma rede e tem como objetivo comum adquirir novas competências que viabilizem inovações. Essa discussão será aprofundada na próxima seção.

\subsection{Aprendizagem interorganizacional, alianças e vantagem competitiva}

No atual ambiente de negócios e de gestão, caracterizado por uma concorrência cada vez mais acirrada a partir do aumento do uso da informação e da tecnologia, além 
de novas demandas tanto para as organizações como para seus diversos tipos de atores sociais envolvidos tem crescido a utilização de abordagens gerenciais baseada nos princípios das redes sociais tais como a cooperação, a parceria e complementaridade, dentre elas as alianças estratégicas e as novas práticas de aprendizagem interorganizacional (Andreis et al, 2014).

Wegner (2011, p. 540) define a aprendizagem interorganizacional como aquela que "ocorre no contexto de grupos de organizações que cooperam proativamente". Inserida nessa abordagem, destacase a aprendizagem em rede, que não se trata meramente da soma da aprendizagem dos indivíduos e das organizações que compõem a rede, e sim é caracterizada por mudanças em propriedades no nível da rede. É a partir da interação e das relações entre os participantes que a aprendizagem interor-ganizacional é possível e seus efeitos podem ser percebidos nas organizações que compõem as redes.

Child, Faulkner e Tallman (2005) destacam que dentre as diferentes motivações que levam uma organização a interagir com outras organizações está a necessidade de adquirir novas competências que viabilizem inovações de reconhecido valor econômico no mercado. A aprendizagem interorganizacional está no centro das práticas de inovação (Ferreira; Schreiber; Puffal, 2016). Através da colaboração e alianças, as organizações parceiras podem trocar conhecimentos e aprender umas com as outras, constituindo assim um meio para a renovação de competências essências (Andreis et al, 2014; Child, 2011; Hamel \& Prahalad, 1995; Cohen \& Levinthal, 1989).

Diante das incertezas ambientais, as organizações são constantemente desafiadas a buscarem maneiras de se sustentar e crescer no mercado no qual atuam, sendo fundamental a aquisição de competências específicas e essenciais para que as mesmas obtenham vantagens competitivas diante de seus concorrentes. Partindo de uma perspectiva multidimensional sobre competências, entende-se que tratam-se da "capacidade que uma organização tem para sustentar alocações coordenadas de recursos a fim de ajudar a empresa a atingir seus objetivos" (Heene \& Sanchez apud Leite \& Porse, 2005, p. 62).

$O$ desenvolvimento de competências na empresa é o resultado da integração do conhecimento. Deste modo, torna-se necessário a habilidade em alinhar e integrar o conhecimento - criado pela organização e adquiridos pela interação com outras organizações, considerando que, quanto mais amplo se constituir o escopo desse conhecimento integrado em uma competência, maior será a dificuldade de imitação por parte das empresas concorrentes (Oliveira Jr., 2001).

Oliveira Jr. (2001) destaca que por meio de colaboração e alianças, organizações parceiras podem trocar conhecimento e aprender uns com os outros, o que constitui 
um veículo para nova aprendizagem organizacional e para a renovação das competências essenciais da empresa. Por outro lado, o mesmo autor destaca que o principal papel da empresa consiste na administração de seu conhecimento de forma mais eficiente que seus competidores, cabendo a organização identificar e proteger seu conhecimento estrategicamente relevante. Lei; Hitt e Bettis (2001) atribui aos níveis mais altos da administração a responsabilidade em desenvolver capacidades de constituir processos e produtos de difícil imitação na busca por vantagem competitiva.

Nesses termos, a cooperação tornouse uma importante estratégia para empresa em situação desvantajosa no mercado ou que pretendem ampliar suas condições de competição em um ambiente dinâmico (Wegner, 2011, p. 538). Por outro lado, constata-se que embora haja colaboração e alianças entre as organizações, cada empresa irá (ou deverá) possuir sua capacidade idiossincrática, em que é preciso maximizar o valor através do desenvolvimento dos recursos, assim como, da integração e combinação de conhecimento estrategicamente relevante e de competências essenciais.

Além disso, Wegner (2011, p. 542) destaca que o processo de aprendizagem interorganizacional "não se trata de um avanço contínuo e ininterrupto: há retrocessos, ajustes e reveses" influenciado sobre vários elementos considerados moderadores na promoção dessa aprendizagem (Child, 2011), temática da próxima seção.

É pertinente destacar a relevância de compreender os fatores moderadores e como eles interferem no processo de aprendizagem, considerando que os conhecendo e gerenciando-os é possível analisar e aperfeiçoar as práticas e estratégias de aprendizagem utilizadas pelas organizações.

\subsection{Elementos moderadores da aprendi-za- gem em redes}

Entende-se como elementos moderadores da aprendizagem aqueles fatores que exercem influência positiva (fomento/promoção da aprendizagem) ou negativa (inibição/interrupção da aprendizagem) em uma ou mais das etapas do ciclo de aprendi-zagem: compreensão - ação - interpretação incorporação do conhecimento na organização.

Wegner (2011), fundamentando-se em outros autores, destaca alguns elementos considerados moderadores na promoção da aprendizagem interorganizacional. De modo semelhante, Wilk, Van de Bosch e Volberda (2003), também destaca alguns fatores que exercem influência na aprendizagem, estando esses associados às características das redes.

Conforme Wegner (2011), os elementos moderadores da aprendizagem interorganizacional podem ser agrupados em três categorias: elementos do contexto geral (pressão do ambiente concorrencial das empresas e competição pelo mesmo mercado); elementos do nível da rede (nível de confiança/qualidade das relações, rea-ções de poder entre os participantes, mecanismos de controle, mecanismos de informação/comunicação, e existência de objetivos compartiIhados); e elementos no nível da empresas 
participantes (predisposição dos participantes em aprender, e conhecimentos complementares). Wilk, Van de Bosch e Volberda (2003), destacam os fatores que exercem influência na aprendizagem associados as próprias características das redes: densidade estrutural e relacional, capital social, confiança, intenções, receptividade, capacidade absortiva, ambiguidade, hierarquia e integração.

É importante destacar que a variável "tempo" é determinante no processo de aprendizagem e criação do conhecimento. Child (2011) destaca que a aliança cooperativa se desenvolve enquanto relacionamento ao longo do tempo, em termos de um ciclo de vida. Conforme o autor, o tipo de aprendizagem gerada em rede vai depender do propósito, do envolvimento e das necessidades dos parceiros, e todos esses elementos podem ser modificados ao longo do tempo, ou seja, ao longo das diferentes fases de desenvolvimento da rede: contatos iniciais, formação, desenvolvimento e consolidação. Assim, é preciso atentar que a variável tempo tanto pode influenciar positivamente nesse processo de aprendizagem, quanto pode ser um fator limitante.

Assim, observa-se que o fator tempo pode contribuir, tendo em vista que o amadurecimento da relação empresarial tende a gerar maior interação e ampliação dos contatos entre os participantes e, consequentemente, mais confiança no grupo e disposição para a troca de informações, gerando assim aprendizagens sistêmicas e até estratégicas.
Por outro lado, com o passar do tempo, a relação em rede pode não ser mais vantajosa, considerando que pode-se chegar a um momento em que não há mais tanto aprendizado e os membros da rede podem não ter mais interesse em continuar participando da aliança cooperativa, seja por mudança de propósitos ou de necessidades, seja pela desmotivação em continuar devido à falta de aprendizado.

Além disso, é importante ainda ressaltar que o tempo cronológico não é sinônimo de amadurecimento. Conforme Wegner (2001) destaca o tempo de existência da rede não é condição suficiente para assegurar níveis mais avançados de aprendizagem, mas sim o amadurecimento. É por meio da maturidade da relação cooperativa (e isso não se limita à questão temporal) que os participantes passam da troca de informações elementares para outras mais estratégicas.

Em síntese, buscou-se evidenciar nesse estudo que tão importante quanto a aprendizagem organizacional pode acontecer em rede (Wegner, 2011; Levinthal \& March, 1993) e que a cooperação e as alianças estratégicas para aprendizagem podem ser muito benéficas para as organizações (Oliveira Jr., 2001, Gulatti, 1998), entretanto, é preciso considerar a existência e influência de uma série de fatores que tanto podem facilitar quanto dificultar o processo de aprendizagem (Wegner, 2011; Child, 2011; Wilk, Van de Bosch, Volberda, 2003).

\section{PROCEDIMENTOS METODOLÓGICOS}


Essa pesquisa caracteriza-se como um estudo de caso descritivo de abordagem qualitativa (Yin, 2005). Para a coleta de dados foram realizadas entrevistas semiestruturadas (Manzini, 2003) com quatro gestores de uma rede hoteleira paraibana composta por três empre-endimentos localizados no município de João Pessoa-PB.

As entrevistas foram realizadas no mês de novembro de 2016, todas registradas por meio de um gravador de áudio, com autorização prévia dos participantes. O instrumento de coleta de dados (roteiro de entrevista) consistia em 21 questões segmentadas em 4 seções temáticas: 1) perfil do entrevistado, dos meios de hospedagem e da Rede; 2) o processo de aprendizagem interorganizacional; 3) a relação de cooperação/competição e as alianças estratégicas para aprendizagem; e 4) os fatores moderadores da aprendizagem em rede.

Quadro 1 - Roteiro da Entrevista Semiestruturada - Questões centrais utilizadas na coleta de dados

\begin{tabular}{l}
1 Perfil do entrevistado, dos meios de hospedagem e da Rede \\
Gênero? Formação? Cargo? Tempo de atuação na rede e no cargo? Ano de fundação da Rede? \\
Número de meios de hospedagem administrado pela Rede? Estrutura Organizacional? \\
\hline 2 Processo de aprendizagem interorganizacional \\
Como é feita a aquisição de conhecimento? Como é realizada a distribuição de conhecimento? \\
Como se dá o processo de gestão de conhecimento na rede? Em que consiste a memória organiza- \\
cional? A aprendizagem nos hotéis da rede é passada do nível individual para organizacional ou o \\
contrário da organização para o indivíduo? \\
\hline 3 Relação de cooperação/competição e as alianças estratégicas para aprendizagem \\
Há troca de conhecimentos em todos os níveis entre os gestores da Rede e os gestores de outros \\
meios de hospedagem? É feito o uso da tecnologia, como por exemplo de redes sociais? \\
Como se dá a relação entre os gestores do grupo e os gestores dos demais hotéis? Essa relação é \\
de cooperação ou competição? \\
Ao seu ver, organizações concorrentes podem ser parceiras? \\
É possível ganhar vantagem competitiva aliando-se aos concorrentes? \\
\hline 4 Fatores moderadores da aprendizagem em rede \\
Nos hotéis administrados pela rede há bloqueios relacionados à limitação de papel, limitação de \\
absorção de conhecimento, limitação de público ou aprendizagem situacional? \\
Há fatores contextuais da Rede que inibem a aprendizagem? \\
Quanto ao processo de "desaprender", como é realizado na Rede para a retirada de "vícios" ou \\
práticas que não condizem com o que é esperado dos funcionários?
\end{tabular}

Fonte: Elaboração própria (2017)

As entrevistas foram previamente agendadas e todas foram realizadas na Unidade II, da Rede onde está localizado o escritório administrativo do Grupo. Após a coleta de dados e a transcrição das entre-vistas, foi realizada a organização dos dados por categorias de análise: 1) aquisição e transferência de conhecimento entre os hotéis do grupo e os demais hotéis da cidade; 2) memória organizacional; 3) relação de cooperação/competição; 4) alianças estratégicas; e 5) os elementos moderadores da aprendizagem interorganizacional, que se 
dividem em três subcategorias, como pode ser observado no Quadro 2.

Quadro 2 - Categorias de Análise da Pesquisa

\begin{tabular}{|c|c|c|}
\hline Categorias de Análise & Subcategorias de Análise & Literatura base - Autores \\
\hline $\begin{array}{l}\text { Aquisição e transferência de } \\
\text { conhecimento em rede }\end{array}$ & $\begin{array}{l}\text { - Interorganizacional - no } \\
\text { nível do grupo hoteleiro em } \\
\text { estudo; } \\
\text { - Em rede-entre os hoteis do } \\
\text { grupo e demais hotéis da } \\
\text { cidade. }\end{array}$ & $\begin{array}{l}\text { Andreis et al (2014) } \\
\text { Wegner (2011); } \\
\text { Crossan, M. M., Lane, H. W., \& } \\
\text { White, R. E. (1999); } \\
\text { Starkey (1998); } \\
\text { Huber (1991). }\end{array}$ \\
\hline Memória Organizacional & -- & $\begin{array}{l}\text { Starkey (1998); } \\
\text { Huber (1991). }\end{array}$ \\
\hline $\begin{array}{lc}\text { Relação } & \text { de } \\
\text { Cooperação/Competição } & \\
\end{array}$ & -- & $\begin{array}{l}\text { Oliveira Jr. (2001) } \\
\text { Hamel e Prahalad (1995) }\end{array}$ \\
\hline Alianças Estratégicas & -- & $\begin{array}{l}\text { Gulatti (1998) } \\
\text { Cohen \& Levinthal (1989) }\end{array}$ \\
\hline $\begin{array}{l}\text { Elementos moderadores } \mathrm{da} \\
\text { Aprendizagem }\end{array}$ & $\begin{array}{l}\text { - Elementos do contexto } \\
\text { geral; } \\
\text { - Elementos do nível da rede; } \\
\text { - Elementos relacionados às } \\
\text { próprias características das } \\
\text { empresas. }\end{array}$ & $\begin{array}{l}\text { Wegner (2011); } \\
\text { Child (2011); } \\
\text { Wilk, Van de Bosch e Volberda } \\
\text { (2003). }\end{array}$ \\
\hline
\end{tabular}

Fonte: Elaboração própria (2017)

No Quadro 1 é possível observar as categorias de análise do estudo bem como os autores utilizados para a compreensão de cada uma delas, já que para a análise foi realizada a relação entre os dados e a literatura abordada na fundamentação teórica desse estudo.

Por fim, é pertinente destacar que para preservar a identidade dos participantes, adotou-se a utilização da sigla E1, E2, E3 e E4 para se referir ao entrevistado 1, entrevistado 2 , entrevistado 3 e entrevistado 4. Na próxima seção serão apresentados os resultados da pesquisa.

\section{RESULTADOS}

A apresentação e análise dos resultados seguiu a mesma estrutura do roteiro de entrevista utilizado na coleta de dados, que compreende 4 seções: a primeira buscava levantar informações sobre o perfil dos entrevistados, dos meios de hospe-dagem e do Grupo Hoteleiro o qual faz parte; a segunda seção tinha como objetivo compreender como ocorre o processo de aprendizagem interorganizacional; a terceira seção buscava identificar a percepção dos entrevistados sobre a relação de cooperação/competição e sobre as alianças estratégicas para a aprendizagem na hotelaria de João Pessoa-PB, e, por fim, a quarta parte do roteiro buscava analisar os fatores moderadores da aprendizagem 
interorganizacional, na Rede de Hotéis em estudo.

\subsection{Perfil dos sujeitos da pesquisa e o grupo hoteleiro em estudo}

Participaram da Pesquisa os Diretores Comercial e Financeiro, e os Gestores Comercial e Financeiro, profissionais responsáveis pela gestão dos três hotéis pertencentes ao Grupo Casa Branca, fundada há 5 anos, em João Pessoa-PB. Todos os entrevistados são do gênero masculino e possuem ensino superior, as formações são em: contabilidade, administração, direito e gestão hoteleira. Os diretores entrevistados são também fundadores do Grupo, e os outros dois participantes da pesquisa já estão na rede há mais de um ano, e mesmo antes de entrar no grupo já tinham vivenciado outras experiências profissionais em hotéis.

Conforme os entrevistados, o Grupo Casa Branca surgiu sob a premissa de trazer ao mercado um produto diferenciado, que pudesse reunir requinte, sofisticação e qualidade a um preço atraente. Assim, surgiu o primeiro equipamento hoteleiro: a Pousada Casa Branca Unidade 1. Logo depois, devido aos bons resultados e o crescimento da demanda, foram abrindo as demais unidades.

Atualmente, o grupo dispõe e administra três empreendimentos hoteleiros: a Unidade I, a Unidade II e a Unidade III, denominada Executive. Em todos os empreendimentos há quartos para acomodação de até quatro pessoas e são servidos café da manhã, com valor já incluso na diária. A uni dade III se destaca ao ser comparado aos demais meios de hospedagem do grupo, pelo seu requinte e sofisticação.

Por outro lado, de acordo com o site institucional da Rede, a qualidade do serviço prestado pela rede é a mesma. O Grupo Casa Branca tem "tradição em servir bem", sendo sua característica treinar os seus colaboradores através de parcerias com organizações específicas, assim como, filiados a instituições envolvidas com análise de práticas e capacidades inovativas e programas de qualidade.

Na próxima seção serão apresentados os dados referentes ao processo de aprendizagem interorganizacional, na qual será possível compreender como acontece o processo de aquisição e troca de conhecimentos entre os hotéis, bem como, compreender como se constitui a memória organizacional do grupo.

\subsection{0 processo de aprendizagem interorga- nizacional: aquisição e compartilha- mento de conhecimentos e memória organizacional}

Reconhecendo a necessidade e relevância da organização aprender tanto com o desenvolvimento interno do conhecimento obtidos e desenvolvidos pela própria organização; quanto com a experiência de outras organizações, considerando a complementaridade entre essas aprendizagens (Wegner, 2011; Levinthal \& March, 1993), foram realizados alguns questionamentos sobre a relação existente entre os hotéis administrados pelo Grupo Casa Branca entre si, bem como, com os demais hotéis bandeiras. 
No que se refere à aquisição e transferência de conhecimento entre os hotéis da rede e os demais, todos os entrevistados informaram que há uma constante troca de informações. Dois dos participantes da pesquisa enfatizaram que essa transferência de conhecimento acontece com frequência no que se refere a assuntos comerciais e operacionais, já no que diz respeito à questão financeira ainda há uma dificuldade de comunicação.

Na parte comercial e operacional, sim. Na parte financeira, não... porque não tem quem escute. Não se fala sobre isso. O cara tem medo de conversar com você. É a mesma coisa que você conversar de morte (...) Então, operacionalmente e comercialmente nós nos comunicamos excelentemente bem. Mas com relação à parte financeira é bem complicado (E2).

O conhecimento pode até ser compartiIhado no setor comercial, no operacional... mas no financeiro não. Posso falar por minha área. No financeiro, não existe isso. Pelo menos não diretamente (...)Eu não tenho acesso a essas informações de outros hotéis. Pelo contrário, cada um que guarde o seu. Mas o que vejo dos outros setores, principalmente comercial, é que há uma cooperação (E4).

O E3 aponta que a transferência de conhecimento entre os hotéis acontece muito mais em nível técnico e operacional:

No nível gerencial, acho que cada um já tem suas diretrizes e decisões, então, normalmente, a gente não compartilha esse tipo de conhecimento, porque cada um já trabalha em um caminho, em cima de uma reta. Então, não tem essa de eu vou fazer essa ação de venda e vou combinar com o hotel $x$. Isso não existe (E3).

Em concordância, o E4 apresentou possíveis explicações para isso ocorrer: "são sistemas diferentes, estratégias diferentes, formas diferentes de se trabalhar. Cada um tem a sua forma".

Ainda sobre a transferência de conhecimentos entre os hotéis da rede, os participantes da pesquisa destacaram a facilidade nas trocas de informações com o avanço da tecnologia. Conforme o E4, na Rede é comum o uso do aplicativo WhatsApp para a troca de experiências e conhecimentos entre os profissionais de diversos setores do hotel: "questão de escalas, de folgas, isso a gente consegue resolver rápido pelo whatsApp. A tecnologia veio para ajudar".

O E1 relata a relevância das tecnologias para o Grupo Casa Branca:

\begin{abstract}
A gente tem um grupo com todos os funcionários e temos skipe em todos os computadores dos hotéis. Um problema de outro hotel a gente fica sabendo daqui e muitas vezes daqui mesmo solucionamos. Isso é o nosso dia a dia! O bom dia da gente é: tem um problema com o café da manhã, a camareira não chegou. O bom dia da gente é resolver problema hoje pelo WhatsAap (E1).
\end{abstract}

A utilização do mencionado aplicativo se estende e é eficaz também nas relações de comunicação entre os gestores do grupo 
Casa Branca e os demais gestores de hotéis da cidade, conforme relata o E1:

\begin{abstract}
Pelo whatsApp pessoal... eu tenho o telefone de fulano, então vou me comunicando... A gente tem grupos, mas os grupos são mais para discussões sobre o turismo como um todo e como ações que a gente pretende fazer, mas analisando de uma forma mais geral. Essa troca de conhecimento é mais pessoal.
\end{abstract}

Tão importante quanto adquirir conhecimento fora da organização é armazená-lo dentro da organização. Sob esse aspecto, memória organizacional, considerada como um armazém no qual todo o conhecimento é guardado para ser utilizado no futuro (Huber, 1991), os entrevistados informaram que nos hotéis administrados pelo Grupo Casa Branca existem os manuais referente à normas e aos procedimentos padrões.

Aqui a gente tem uma prática que não tem em outras empresas. Eu não tive nas empresas onde eu trabalhava, que é reter o conhecimento na organização. A gente tenta sempre colocar em pastas, tanto via sistema, que é a pasta virtual, quanto física mesmo. Aqui a gente sabe que a gente não é da empresa, e a empresa continua existindo se você sair. Então, nós procuramos manter nosso conhecimento na empresa. Deixar na empresa, para que de alguma forma outras pessoas possam usufruir também (E3)

Sim, sim. Inclusive, antes de eu começar a trabalhar aqui, eu já tinha prestado consultoria aqui. Então, quando eu cheguei, já tinha a rotina que eu tinha passado. E quando eu substituí o antigo (funcionário) a rotina já estava feita... Isso a diretoria deixa muito claro. Que é sempre bom a gente deixar o conhecimento para a empresa. (E4)
Com base nos dados das entrevistas, percebe-se as organizações da rede estudada se comunicam com frequência e compartiIham conhecimentos (tanto entre si quanto com as demais organizações hoteleiras de João Pessoa) de níveis técnicos e operacionais, em especial, no que se refere a assuntos comerciais. Observa-se ainda que há inclusive a preocupação de armazenar o conhecimento adquirido nessas relações na própria organização, o que constitui a memória organizacional (Huber, 1991). Essas constatações evidenciam a relação de mútua confiança entre os gestores da rede hoteleira estudada com os demais gestores da hotelaria pessoense e a aspiração pelo crescimento coletivo, em rede. Na próxima seção, serão enfatizadas a relação de cooperação e as alianças estratégicas firmadas entre essas organizações hoteleiras.

\subsection{A relação de cooperação/competição entre os hotéis e as alianças estratégi- cas para a aprendizagem na hotelaria de João Pessoa-PB}

Em João Pessoa, na Paraíba, há três hotéis administrados pelo Grupo Casa Branca e assim foi questionado se é observado algum tipo de competição entre esses hotéis da rede. $O$ entrevistado 3 esclareceu que não: "eu por exemplo que sou do setor comercial tenho obrigação de manter todos os hotéis cheios, lotado. Não existe isso de um superar o outro. Eu tenho que manter os três lotados". O E4 complementa:

Competição? Não! Todos se ajudam. O recepcionista entra a tarde, ele sabe 
qual é a ocupação, ai ele informa ao pessoal do grupo: "Ó! Só tenho uma vaga!", ai o pessoal parabeniza porque ta quase lotado e tal. E ai fica assim, se algum recepcionista vê que a ocupação ta baixa e ele informa, aí o pessoal volta os olhos para onde ele tá. Então se chegar alguém para fazer a reserva em outra unidade e, para aumentar a ocupação daquele que tá baixo, já encaminha para lá. Eles se ajudam bastante.

Conforme os entrevistados informaram, a relação é de cooperação, pois por mais que estejam localizados em uma mesma região e possuam a mesma marca, cada um tem sua fatia de mercado, devido suas características próprias, corroborando com que afirma Oliveira Jr. (2001) ao tratar das capacidades idiossincráticas das organizações, resultado da combinação de conhecimento estrategicamente relevante e de competências essenciais.

Para Oliveira Jr. (2001) são considerados recursos intangíveis e idiossincráticos que podem proporcionar vantagem competitiva para a empresa, a melhor integração entre suas muitas atividades de forma a poder responder mais rápido a demandas do mercado, o maior comprometimento da força de trabalho de forma a proporcionar melhor serviço aos clientes, alta taxa de produtos inovadores e de boa qualidade que ajudem a atrair clientes.

$$
\text { O E1 exemplificou como acontece a }
$$
cooperação entre os hotéis do Grupo Casa Branca e demais hotéis da cidade, ressaltando, inclusive, que a parceria e as alianças, em alguns casos, são mais importantes do que às vantagens econômicas.

É... essa relação hoje ela acontece em João Pessoa da forma mais sadia possível. Hoje eu tô com uma demanda interna administrativa que eu não sei como os outros hotéis se comportam, eu pego meu telefone faço três ligações e fico sabendo. Então, existe uma transparência muito grande e uma troca de conhecimento muito grande. Então, desde a parte administrativa, a parte comercial, como a parte de vendas... Tô lotado, eu digo: ó, tô com o "over" de 10 apartamentos, tu tens 10 apartamentos para esse final de semana? - Tenho! - Vou mandar para tu, a tarifa é essa. Tu consegues fazer? - Consigo. Minha tarifa é mais alta, mas eu consigo. Então... quer dizer, a gente tem uma relação extremamente sadia, com os outros hotéis (E1).

Estou aqui há um ano e sempre observei essa relação de cooperação e até em outros grupos eu sempre batalhei por isso. Acho que a união faz a força. Tem hostel que entra em contato que precisa de ajuda, porque tá lotado e a gente recebe aqui, mesmo tendo uma tarifa mais alta, cobrando o preço deles (E3).

O E2 enfatiza a cooperação entre os gestores da hotelaria paraibana, mas destaca as limitações e fragilidades do conhecimento compartilhado.

Eu acho que existe sim uma cooperação entre os hotéis. Acho que essa cooperação, essa troca de informação é bem legal. Mas a parte de conhecimento em si, é extremamente deficitária. A hotelaria pessoense hoje trabalha, em relação à Europa, na Era Medieval. Com a diferença que nós usamos computadores 
(...) E não é uma coisa que só existe em João Pessoa. É um fato que existe no Brasil como um todo.mas, a troca de informação na parte comercial, na operação da hotelaria mesmo em si, é show! (E2).

Além das trocas de informações e colaboração existente dentro do Grupo Casa Branca há também essa mesma postura e prática entre os hotéis da rede e os demais hotéis. O entrevistado destacou algumas situações que demonstram a cooperação entre os meios de hospedagem.

No dia a dia, tem cooperação com força. O pessoal se ajuda mesmo. Tipo assim, se a gente tiver lotado aqui, quando eu tinha duas unidades e lotava, eu ficava ligando pra o pessoal. E dizia: “Ó, bicho, tem vaga? - Tem. - Tô mandando pra aí!" Chegava solicitação de reserva pra mim e eu dizia: Eu não tenho não, mas eu tenho parceiro e tal. Isso arrisca de você entregar seu cliente a outro. Porque se ele for lá e gostar, ele vai lá (E2). Eles são muito ligados, a cooperação é muito grande. Se eles participam de um evento, eles viajam juntos, dividem quartos, trocam informações. Então, eles se ajudam bastante (E4).

Ao questionar sobre a relevância das alianças estratégicas para aquisição de vantagem competitiva para a Rede, os entrevistados informaram que acredita que apesar de existir um risco em trocar informações e conhecimentos, a cooperação é o melhor caminho, pois todos saem ganhando.

Ao meu ver, balanceado o risco e o benefício, o benefício é muito maior, então, vale muito mais a pena correr o risco dando informação, enquanto um gerente financeiro meu ganha, de quanto uma operadora minha ganha, do que eu segurar essa informação e não ter acesso a informações que eu acho pertinente. Então, eu acho que o benefício é muito mais que o risco (E1).

Aqui a gente comenta muito isso. Quando a gente sai para fazer uma ação fora, por exemplo, a gente vai para divulgar o destino, porque eu lotando meu hotel sobra para o outro, o outro hotel lotando sobra para mim. Então nesse foco ai somos unidos, não tem uma competição não (E3).

O E2 enfatiza que essa relação de cooperação é uma característica da Hotelaria Pessoense:

a gente tem uma relação é entre empresas que é muito difícil de se ver. A gente viaja pelo Brasil todo. É muito difícil a gente ver uma união dessa. Nos destinos que a gente passa, inclusive nessa viagem agora, eu sai perguntando, e o pessoal tudo abismado com essa política nossa de ABIH tá na frente, promovendo ações, promovendo a união.

\section{O E3 concorda e complementa:}

Isso é do mercado de João Pessoa, porque quando a gente fala em relação a outros mercados, porque você trabalha com outros mercados paralelos: Pernambuco, Rio Grande do Norte não tem isso. E nós conseguimos identificar que João Pessoa tem essa parceria, essa cooperação. (E3)

\section{O E1 apresenta possíveis explicações} para a existência dessa relação de cooperação na hotelaria pessoense.

Eu costumo dizer é mais fácil a gente ter essa atitude no destino de João Pessoa, que falta leito. Num destino como Recife que são hotéis fechando $35-40 \%$ de ocupação, se torna mais difícil: ah não vou dizer isso, vou fazer uma visita em São Paulo na empresa tal, não conto a ninguém, porque se eu for o cara vai 
querer ir junto, vai lá e vai tomar... o hotel dele é melhor, ele vai fazer uma tarifa mais barata. Então, João Pessoa vive um momento muito positivo, que nos deixa fazer isso. Se isso vai perdurar, se isso não vai mudar... Eu rezo que não mude! Mas para a gente é muito mais fácil hoje tendo em vista o momento que a gente vive (E1).

Ao serem questionados se é possível ter vantagem competitiva aliando-se a concorrentes, todos os entrevistados responderam de forma afirmativa. O E2 destacou: que as alianças são muito positivas, "cada um tem seu diferencial, seu produto bem desenvolvido, elaborado, tudo, então... não tem o que temer".

As informações apresentadas nessa seção ratificam que as organizações, através da colaboração e alianças, podem trocar conhecimentos e aprender umas com as outras, constituindo assim um meio para a renovação de competências (Child, 2011; Hámel \& Prahalad, 1995; Levinston \& Asahi, 1995).

Na próxima seção serão apresentados os dados referentes aos elementos que exercem interferência no processo de aprendizagem interorganizacional.

\subsection{Elementos moderadores da aprendiza- geminterorganizacional}

Conforme exposto na fundamentação teórica desse estudo, a transferência de conhecimento entre organizações pode ser interrompida, devido à existência de elemen- tos moderadores na promoção da aprendizagem interorganizacional (Wegner, 2011; Wilk, Van de Bosch \& Volberda, 2003). Nesse sentido, foram realizados alguns questionamentos sobre esses elementos e os resultados serão apresentados nessa seção.

Como já descrito anteriormente, Wegner (2011) agrupa esses elementos em 3 categorias: os elementos do contexto geral, elementos do nível da rede, os elementos relacionados ao nível das empresas participantes. Wilk, Van de Bosch e Volberda (2003) descrevem os fatores que exercem influência na aprendizagem associados às próprias características das redes.

No que se refere aos elementos do contexto geral, foi possível observar nos relatos dos entrevistados que não há uma pressão do ambiente concorrencial das empresas ou competição pelo mesmo mercado. O E2 reconhece que existe uma competição natural entre os hotéis, mas explica a cooperação existente no dia a dia da hotelaria pessoense.

\begin{abstract}
Existe a competição natural, principalmente em eventos, existe, até porque você tá ali pra se vender. Desculpa, todo mundo tá ali pra se vender. Então, se tá todo mundo ali se vendendo, tem que cada um correr atrás do seu, né? Mas no dia a dia, tem cooperação com força. $O$ pessoal se ajuda mesmo. (E2).
\end{abstract}

Do mesmo modo, ficou perceptível a existência da confiança entre os gestores da empresa, marcada por relações positivas, com clareza nas informações/comunicações e pela existência de objetivos compartilha- 
dos: dentre esses, divulgar o destino Paraíba (elementos moderadores do nível da rede).

Sim.... se eu tenho uma dificuldade numa determinada área, eu ligo para o diretor, pergunto... se eu tenho uma necessidade de... um problema operacional, então eu ligo para um líder operacional de outro hotel, ou para a gestão operacional e tiro a dúvida. Enfim... há uma troca baseada na confiança (E1).

Quando a gente sai para fazer uma ação fora, por exemplo, a gente vai para divulgar o destino, porque eu lotando meu hotel sobra para o outro, o outro hotel lotando sobra para mim (E3).

Quanto aos elementos no nível do grupo em estudo (predisposição dos participantes em aprender, e conhecimentos complementares), os entrevistados informaram que o Grupo sempre está buscando se atualizar e aprender, assim como compartilha seu conhecimento com os demais gestores.

A gente tá com 4 anos... está em expansão e o discurso da gente e a atitude da gente mostram que a gente vem correndo atrás de conhecimento, de se aperfeiçoar cada vez mais. Teoricamente, A gente age dessa forma e subentende que eles estão na mesma "vibe". Vamos correr atrás de conhecimento, que as oportunidades aparecem para todos. (E1).

A cultura organizacional da empresa exige aprendizagem continuada deles. É um dos valores do endomarketing nosso que a gente prega muito. Aqui temos uma cultura de desenvolvimento pessoal, cultura de passagem de conhecimento, cultura de desenvolvimento de liderança. (E2).

Além dos fatores moderadores da aprendizagem interorganizacional apresentadas por Wegner (2011), observou-se também nesse estudo os fatores que exercem influência na aprendizagem associados às próprias características das redes, descritos por Wilk, Van de Bosch e Volberda (2003), tais como a densidade estrutural e relacional, capital social, confiança, intenções, receptividade, capacidade absortiva, ambiguidade, hierarquia e integração.

O E2 descreveu uma situação que evidencia alguns desses aspectos, tais como a densidade relacional e a confiança entre os gestores hoteleiros e até gestores de outros segmentos, assim como a receptividade e capacidade absortiva do Grupo Casa branca.

\begin{abstract}
Há umas duas semanas, um dono de restaurante aqui, um dos maiores restaurantes daqui, um restaurante excelente, disse no grupo que tinha adquirido uma planilha financeira. [Eu trabaIho com finanças há 2 anos e meio. Inicialmente o E4 me ensinou muita coisa, depois o curso me obrigou a aprender muita coisa e o E4 é contador, e eu sou financista. Então, as disciplinas se complementam.] Foi que eu fiz? Peguei. Ele disse: Alguém quer a planilha? Eu disse "quero". Aí ele mandou. (E2).
\end{abstract}

Uma variável importante no processo de aprendizagem e criação do conhecimento em redes destacado por Child (2011) é o tempo. Conforme o autor, o tipo de aprendizagem gerada em rede vai depender do propósito, do envolvimento e das necessidades dos parceiros, e todos esses elementos podem ser modificados ao longo do tempo, ou seja, ao longo das diferentes fases de desenvolvimento da rede: contatos iniciais, forma- 
ção, desenvolvimento e consolidação. Nesses termos, foi perguntado se demorou para existir essa cooperação entre os hotéis. O E4 informou que "isso já vem de muito tempo". Os demais ratificaram que isso sempre existiu na hotelaria pessoense.

Por fim, questionou-se se existem encontros, reuniões entre os gestores dos hotéis do Grupo com os gestores de outros hotéis para a realização dessas trocas de conhecimento. Os entrevistados afirmaram que há uma amizade entre esses profissionais e que os encontros acontecem informalmente $e$ durante as viagens para participar de feiras e outros eventos fora do estado, conforme já apresentado em relatos nesse estudo.

Nesses termos, conclui-se que a cooperação tornou-se uma importante estratégia para as organizações ampliarem suas condições de competição em um ambiente dinâmico (Wegner, 2011; Child, 2011; Hamel \& Prahalad, 1995; Levinston \& Asahi, 1995).

\section{CONSIDERAÇÕES FINAIS}

Esse estudo demonstra uma mudança no foco dos negócios: as organizações em rede deixam de agir de modo implacavelmente egoísta e ganancioso, passando a adotar uma postura mais saudável em busca de uma comunidade próspera. Solomon (2006, p. 38) destaca que "os negócios são acima de tudo interação social e cooperação num sentido sofisticado não uma competição vulgar. São produtividade, não mera busca de lu- cro". Em outros termos, no mundo corporativo não precisa ter um ganhador e um perdedor, é totalmente possível uma relação ganha-ganha. Por meio da aprendizagem interorganizacional e em rede, os arranjos corporativos e as alianças estratégicas, por exemplo, todas as organizações envolvidas poderão ser beneficiadas.

No estudo, verificou-se que não há uma pressão do ambiente concorrencial das empresas ou competição pelo mesmo mercado, assim como é perceptível há confiança entre os gestores da empresa, marcada por relações positivas, com clareza nas informações/comunicações, pela existência de objetivos compartilhados, e a predisposição dos participantes em aprender, e conhecimentos complementares.

Constatou-se ainda que além das aquisições e trocas de conhecimento e colaboração entre os hotéis do Grupo Casa Branca, há também essa mesma postura e prática entre os hotéis do Grupo e os demais hotéis. Além disso, observou-se o quanto as inovações tecnológicas ajudam nesse processo, tendo em vista, por exemplo, que o aplicativo WhatsApp é utilizado para a troca de experiências e conhecimentos entre os profissionais de diversos setores do hotel de forma rápida e eficiente.

Os achados ratificam que as organizações, através da colaboração e alianças, podem trocar conhecimentos e aprender umas com as outras, constituindo assim um meio para a renovação de competências (Child, 2011; Hamel \& Prahalad, 1995; Levinston \& 
Asahi, 1995). Conclui-se ainda que embora haja colaboração e alianças entre as organizações, cada empresa irá (ou deverá) possuir sua capacidade idiossincrática (Oliveira Jr., 2001), assim como, se fazem necessárias a integração e combinação de conhecimento estrategicamente relevante e de competências essenciais para a obtenção de vantagem competitiva.

Por fim, cabe ressaltar que esse estudo é um esforço inicial na compreensão do processo de aprendizagem interorganizacional no contexto da hotelaria. Outros estudos, inclusive em outros segmentos do mercado, podem trazer novas contribuições.

\section{REFERÊNCIAS}

Andreis, A., Prantz, C., Larentis, F., \& de Ávila Dias, D. T. (2014). Aprendizagem Interor-ganizacional: um estudo de caso na empresa Alfa. Revista Inteligência Competitiva, 4(2), 39-55.

Child, J. (2011). Learning throught strategic aliances. In: DIERKES, M.; BERTHOIN ANTAL, A.; Child, J. \& Nonaka, I. (Ed.). Handbook of organizational learning and knowledge. Oxford: Oxford University Press, p. 308-326.

Child, J., Faulkner, D. \& Tallman, S. (2005). Cooperative strategy: managing alliances, networks, and joint ventures. 2. ed. New York: Oxford.

Cohen, W. M., \& Levinthal, D. A. (1989). Innovation and learning: the two faces of $R \& D$. The economic journal, 99(397), 569-596.

Crossan, M. M., Lane, H. W., \& White, R. E. (1999). An organizational learning framework: From intuition to institution. Academy of management review, 24(3), 522-537.
Easterby-Smith, M., \& Lyles, M. A. (Eds.). (2011). Handbook of organizational learning and knowledge management. John Wiley \& Sons.

Ferreira, K. L., Schreiber, D., \& Puffal, D. P. (2016). Análise reflexiva do turismo em saúde à luz da inovação. Revista Brasileira de Pesquisa em Turismo, 10(2), 254-273.

Gherardi, S. \& Nicolini, D. (2001). The sociological foundations of organizational learning. In: DIERKES, M. et al. (Org.) Organizational learning and knowledge. Oxford: Oxford University Press, p. 35-60.

Godoy, A.S. \& Antonello, C.S. (2011). Aprendizagem Organizacional e as Raízes de Sua polissemia. In: Antonello, C.S. \& Godoy, A.S. (Org.) Aprendizagem Organizacional no Brasil. Porto Alegre: Bookman, p. 31-50.

Grupo Casa Branca. (2017). Grupo Casa Branca Hotéis e Pousada. Disponível em: http://www.grupocasabranca.com/. Acesso em: 15 de agosto. 2017.

Gulatti, R. (1998). Alliances and networks. Strategic Management Journal, 19, p. 293-317.

Hamel, G. \& Prahalad, C. K. (1995) Competindo pelo futuro: estratégias inovadoras para obter $\mathrm{o}$ controle do seu setor e criar os mercados de amanhã. Rio de Janeiro: Campus.

Huber, G. (1991). Organizational Learning: the contribuition processes and the literatures. Organizational Science, 2(1), p. 88-115.

Knight, L. (2002). Network learning: exploring learning by interorganizational networks. Human Relations, 55(4), p. 427-454.

Lei, D.; Hitt, M.A. \& Bettis, R. (2001). Competências essenciais dinâmicas mediante a metaaprendizagem e o contexto estratégico. In: Fleury, M. T. L. \& Oliveira Jr., M. M. Gestão Estratégica do Conhecimento: integrando aprendizagem, conhecimento e competências. São Paulo: Atlas, p. 157-186. 
Leite, J. B. D. \& Porse, M.C.S. (2005). Competição baseada em competências e aprendizagem organizacional: em busca da vantagem competitiva. In: Ruas, R.L., Levinthal, D. \& March. J. (1993). The myopia of learning. Strategic Management Journal, 14, p. 95-112.

Levinston, N.; Asahi, M. (1995) Cross-national alliances and interorganizational learning. Organizational Dynamics, 24(20, p. 50-64.

Levitt, B. \& March, J. G. (1988).Organizational Learning. Annual Review of Sociology, 14, pp. 319-340.

Manzini, E.J. (2003). Considerações sobre a elaboração de roteiro para entrevista semi-estruturada. In: Marquezine: M. C., Almeida, M. A. \& Omote; S. (Orgs.) Colóquios sobre pesquisa em Educação Especial. Londrina: Eduel, p. 11-25.

March, J. G. \& Olsen, Johan. P. (1975).The Uncertainty of the Past: Organizational Learning Under Ambiguity. European Journal of Political Research. 3, 147-171.

March, J. G. (1991). Exploration and exploitation in organizational learning. Organization Science, v. $2 / 1$, p. $71-87$.

Nonaka, I., Toyama, R. \& Byosière, P. (2001).A theory of organizational knowledge creation : understanding the dynamic process of creating knowledge. In: DIERKES, M.; Antal, A.B.; Child, J.; Nonaka, I. Handbook of Organizational Learning and Knowledge. New York: Oxford University Press, cap. 22, p. 491-517.

Oliveira Jr., M. M. (2001).Competências Essenciais e Conhecimento na Empresa. In: Fleury, M. T. L. \& Oliveira Jr., M. M. Gestão Estratégica do Conhecimento: integrando aprendizagem, conhecimento e competências. São Paulo: Atlas, p. 122154.
Silva, A. B. (2009). Como os gerentes aprendem?. São Paulo: Saraiva.

Smith, K. G., Gupta, A. K. \& Shalley, C. (2006). The interplay between exploration and exploitation. Academy of Management Journal, 49, p. 693706.

Solomon, R. C. (2006). Ética e Excelência: cooperação e integridade nos negócios. Rios de Janeiro-RJ.

Souza, Y. S. (2004). Organizações de Aprendizagem ou Aprendizagem Organizacional. RAE-Eletrônica - Revista de Administração de Empresas, 3(1), Art.5, Jan/Jun.

Starkey, K.. (1998). What can we learn from the learning organization?. Human Relations, 51(4), p. 531-546.

Takeuchi, H. \& Nonaka, I. (2008). Gestão do Conhecimento. Porto Alegre: Bookman.

Wegner, D. (2011). Aprendizagem Interorganizacional: um estudo das redes horizontais de pequenas empresas. In: Antonello, C.S. \& Godoy, A.S. (Org.) Aprendizagem Organizacional no Brasil. Porto Alegre: Bookman, p. 537-564.

Wilk, R.V., Van De Bosch, F.A.J \& Volberda, H.W. (2003). Knowledge and Networks. In: EASTERBYSmith, M. \& Burgoyne, J. (Org.). The Blackwell handbook of organizational learning and knowledge management. Malden/USA, cap. 30, p. 428-453.

Yin. R. K. (2005). Estudo de caso: planejamento e métodos. 3 ed. Porto Alegre: Bookman.

Informações dos autores 


\section{Jammilly Mikaela Fagundes Brandão}

Professora do Instituto Federal de Brasília - IFB, no eixo Turismo, Hospitalidade e Lazer. Doutoranda em Administração, no Programa de Pós-Graduação em Administração - PPGA. E-mail: jammillybrandao@gmail.com

ORCID: 0000-0002-8826-9762

\section{Joelma Abrantes Guedes Temoteo}

Professora do Departamento de Turismo e Hotelaria DTH, da UFPB. Doutoranda em Desenvolvimento e Meio Ambiente, no PRODEMA.
E-mail: joelma.abrantes@gmail.com

ORCID: 0000-0002-9013-7945

\section{Gesinaldo Ataíde Cândido}

Professos Titular em Administração Geral da UFCG, pesquisador $\mathrm{CNPq}$, Líder de grupo de pesquisa na área de inovação e tecnologia. Docente Permanente junto aos Programas de Pos-graduação das Universidades Federal da Paraíba e Campina Grande. E-mail: gacandido@uol.com.br ORCID: 0000-0002-3112-0254 